\title{
Bir Güneş Enerji Santralinin Elektrik Şebekesindeki Güç Kalitesi Parametrelerine Etkisinin İncelenmesi
}

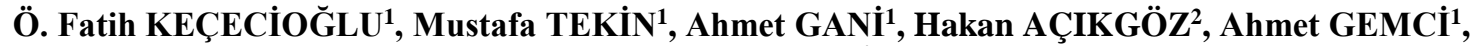 \\ Mustafa ŞEKKEL i ${ }^{*}$ \\ ${ }^{1}$ Kahramanmaraş Sütçü İmam Üniversitesi, Mühendislik - Mimarlık Fakültesi, Elektrik-Elektronik Mühendisliği \\ Bölümü, Kahramanmaraş, Türkiye \\ ${ }^{2}$ Kilis 7 Aralık Üniversitesi, Elektrik-Enerji Bölümü, Kilis, Türkiye
}

\begin{abstract}
ÖZET: Gün geçtikçe artan insan nüfusuna paralel olarak elektrik enerjine olan ihtiyaç da artış göstermektedir. Artan bu elektrik enerjisi gereksinimini karşılamak için geleneksel enerji kaynaklarına ek olarak alternatif enerji kaynakları da son yıllarda sıkça kullanılır hale gelmiştir. Bu alternatif enerji kaynakları kullanılarak elektrik enerjisi elde eden sistemlere güneş enerji santralleri (GES), rüzgar enerji santralleri (RES) ve hidro elektrik santrallerin (HES) örnek olarak verilebilir. Enerji ihtiyacına ek olarak; harmonik, gerilim çökmesi, gerilim yükselmesi, fliker gibi üretilen enerjinin kalitesini temsil eden parametreler de artan teknolojiyle birlikte daha sık görülmekte ve önem arz etmektedir. $\mathrm{Bu}$ çalışmada ise; bir GES'in şebekeye bağlandığı noktanın OG tarafından bir şebeke analizörü vasıtasıyla ölçümler alınmış ve alınan bu veriler harmonik bozulma ve fliker açısından incelenmiştir. Bu incelemeler sonunda şebekede var olan tekil harmoniklerin sınır değerlerin altında kaldığı, akıma ait THB'nin belli zamanlarda kısa süreliğine sınır değerleri aştı̆̆ ve gerilime ait THB'nin gün boyunca sınırı aştığı görülmüştür. Fliker şiddetinin ise genel olarak sınır değerler içinde kaldığı görülmüştür.
\end{abstract}

Anahtar Kelimeler: Enerji Kalitesi, GES, Harmonik, Fliker

\section{Investigation of A Solar Power Plant's Effect over The Power Quality Parameters on Power System}

\begin{abstract}
Electricity energy demand is rising depend on human population which is increasing with each passing day. Alternative energy sources have been used in nowadays for supply this energy demand; in addition to the traditional energy sources. Solar power plant (SPP), wind power plant (WPP) and hydroelectric power plant (HPP) are most important kind of electricity generated systems by alternative energy sources. According to technological development harmonic, voltage sag, voltage swell and flicker are most significant parameters and they play a vital role in the energy quality. In this study some measurements were taken from medium voltage part of section where the SPP in connected to the network by means that network analyzer and these data sets investigated in terms of harmonic distortion and flickers. Three key results observed in this work; values of the odd harmonics, currents of THD and voltage of THD respectively. The odd harmonics were found below the limit values. While currents of THD was exceeding limit values for determined short time, voltage of THD had exceeded limit values for all day time. Although the flicker was not exceeding the limit values.
\end{abstract}

Keywords: Power Quality, SPP, Harmonic, Flicker

\section{GİRIŞ}

"Enerji kalitesi" kavramı, bir ekipmanın kullanım amacına uygun olarak davranışından ve de ömründen herhangi bir kayba uğramaksızın çalışması için öngörülen elektriksel sınırlamalar olarak açıklanabilir [1]. Enerji (güç) kalitesi ve enerji kalitesini etkileyen unsurlar son yıllarda önemli bir araştırma kaynağı olmuştur; çünkü güç kalitesini düzeltmek için gerekli önlemler alınmadan önce, bu tür bozulmaların kaynakları ve nedenlerinin bilinmesi önemlidir. En temel güç kalitesi sorunlarının başında gerilim/akım dalga şeklinin ideal sinüs biçiminden uzaklaşması olarak tanımlanabilir ve bu dalga şekli üzerinde de enerji sistemlerinin dinamikliğinden kaynaklanan istenmeyen gürültüler olabilir. Dalga şeklinin ideal sinüs biçiminden uzaklaşmasının en temel nedeni dağıtım sistemlerinde doğrusal olmayan yüklerin varlığıdır. Enerjinin tüketildiği noktalarda hassas yüklerin son yillarda artış göstermesi, güç kalitesi üzerine yapılan çalışmaları daha da önemli hale getirmiştir. Güç kalitesi sorunlarının başında; gerilim yükselmesi, çökmesi, kesintisi, kırpışması, DC bileşen varlığı, geçici durumlar, harmonikler ve elektromanyetik girişim gelmektedir ve bunlar hassas yüklerin arızalanmasına, transformatörler ve motorlar üzerinde enerji kaybına neden olmaktadır. Tüm bunların sonucunda ise sistem güvenirliği olumsuz 
yönde etkilenmektedir. Bu nedenle, bu tür bozuklukların kaynaklarının ve nedenlerinin bilinmesi, gerekli koruyucu önlemlerin alınmasına büyük ölçüde yarar sağlayacaktır [2].

Güç sistemi üzerinde meydana gelen güç kalitesi problemlerinin çözümü için sistem üzerindeki parametrelerin sürekli ve standartlara uygun olarak izlenmesi gerekmektedir. Bu nedenle güç kalitesi izleme sistemleri, güç sistemlerinin önemli bir parçası haline gelmiştir. Güç sisteminde belirlenen noktalara yerleştirilen izleme sistemleri ile güç kalitesi olaylarının tespiti ve analizi sağlanmaktadır. Bu izleme sistemleri; ölçüm yapılan sisteminin güç kalitesi performansının belirlenmesi, sistemde meydana gelen bozulma türünün ve kaynağının tespit edilmesi, gerekli işletim şartlarının belirlenmesi gibi işletme ve koruma hakkında önemli bilgiler sunmaktadır[3].

Yapılan bu çalışmayla; Adıyaman'nın Gölbaşı ilçesinde kurulmuş olan DAĞPEN AKMKENT isimli güneş santralinin şebekeye bağlandığı noktaya bir şebeke analizörü bağlamak suretiyle sistemden bir haftalık veriler alınmıştır. Elde edilen bu verilerden harmonik ve fliker grafikleri elde edilmiş ve bu grafiklerdeki sonuçlar, Enerji Piyasası Düzenleme Kurumunun "Elektrik Dağıtımı Ve Perakende Satışına İlişkin Hizmet Kalitesi Yönetmeliği"'ne uygun olup olmadığ $\breve{1}_{1}$ araştırılmıştır. Tüm bu araştırmalar neticesinde; standart değerlerin aşıldığı durumlar için çözüm önerileri sunulmuştur.

\section{GÜC KALITESİ YÖNETMELIKLERİ VE ÖLÇME STANDARTLARI}

Orta ve Alçak gerilim dağıtım şebekeleri için güç kalitesi limitlerinin belirlendiği en önemli standart, EN50160 olarak adlandırılan standart olup, pek çok ülkede çevirileri yapılarak kullanılmakta ve ulusal yönetmeliklere temel teşkil etmektedir. EN50160 ile dağıtım şirketleri tarafindan sağlanan elektrik enerjisinin gerilim kalitesi tanımlanmakta ve bu şirketlerin müşterilerine karşı sorumluluklarını ortaya koymaktadır [6]. Türkiye'de ise EN50160 baz alınarak, Enerji Piyasası Düzenleme Kurumu tarafından hazırlanmış "Elektrik Dağıtımı Ve Perakende Satışına İlişkin Hizmet Kalitesi Yönetmeliği” enerji kalitesi değerlendirmelerinde kullanılmıştır. $\mathrm{Bu}$ yönetmeliğe göre;

AG: Etkin değeri 1000 Volt ve altındaki gerilimleri,

Fliker: Yükteki dalgalanmalar nedeniyle ortaya çıkan ve aydınlatma armatürlerinde kırpışmaya yol açan $50 \mathrm{~Hz}$ altındaki gerilim salınımlarını,
Harmonik: Doğrusal olmayan yükler veya gerilim dalga şekli ideal olmayan jeneratörlerden dolayı bozulmaya uğramış bir alternatif akım veya gerilimde, ana bileşen frekansının tam katları frekanslarda oluşan sinüzoidal bileşenlerin her birini,

Maksimum yük akımı (IL): Yük akımı ana bileșeninin etkin değerinin, 15 veya 30 dakikalık ortalama değerlerinin maksimumu şeklinde bulunan akım değerini,

Nominal gerilim (Anma gerilimi): Bir besleme şebekesinin gösterildiği ya da tanıtıldığı ve bazı çalışma karakteristiklerine atıfta bulunan gerilim değerini,

OG: Etkin şiddeti 1000 Voltun üstünden 36 kV'a kadar olan (36 kV dahil) gerilim seviyesini,

Pst: 10 dakikalık periyotlarla ölçülen fliker şiddeti endeksini,

Plt: İki saatlik zaman aralığı boyunca ölçülen (12 ardışık ölçüm) Pst değerlerinden aşağıdaki hesaplanan fliker şiddeti endeksini,

Akım ve gerilime ait toplam harmonik bozulmanın matematiksel ifadesi sırasiyla denklem 1 ve 2 de verilmiştir.

$T H B_{V}=\frac{\sqrt{\sum_{n=2}^{\infty} V_{n}^{2}}}{V_{1}}$
$T H B_{1}=\frac{\sqrt{\sum_{n=2}^{\infty} I_{n}^{2}}}{I_{1}}$

Toplam Talep Bozulumu (TTB): Akım harmonik bileşenlerinin etkin değerlerinin kareleri toplamının karekökünün, maksimum yük akımına (IL) oranı olan ve dalga şeklindeki bozulmayı yüzde olarak ifade eden değeri, temsil eder [7].

Aynı yönetmelikte; gerilim harmoniklerinin sınır değerlerinin verildiği Tablo-1,akım harmoniklerinin sınır değerlerinin verildiği Tablo-2 ve fliker şiddetinin sınır değerlerinin verildiği Tablo-3 verilmiştir. 
Tablo-1 Gerilim Harmonikleri İçin Sınır Değerler [7]

\begin{tabular}{|c|c|c|c|c|c|}
\hline \multicolumn{4}{|c|}{$\begin{array}{r}\text { Tek Harmonikler } \\
\end{array}$} & \multirow{2}{*}{\multicolumn{2}{|c|}{ Çift Harmonikler }} \\
\hline \multicolumn{2}{|c|}{ 3'un Katlarl Olmayanlar } & \multicolumn{2}{|c|}{ 3'un Katları Olanlar } & & \\
\hline $\begin{array}{c}\text { Harmonik } \\
\text { Sirası }\end{array}$ & $\begin{array}{l}\text { Sinır } \\
\text { Değer }\end{array}$ & $\begin{array}{c}\text { Harmonik } \\
\text { Sirası }\end{array}$ & Sınır Değer & $\begin{array}{c}\text { Harmonik } \\
\text { Sirası }\end{array}$ & Sınır Değer \\
\hline$h$ & $(\%)$ & $h$ & $(\%)$ & $h$ & $(\%)$ \\
\hline 5 & $\% 6$ & 3 & $\% 5$ & 2 & $\% 2$ \\
\hline 7 & $\% 5$ & 9 & $\% 1,5$ & 4 & $\% 1$ \\
\hline 11 & $\% 3,5$ & 15 & $\% 0,5$ & $6 \ldots . .24$ & $\% 0,5$ \\
\hline 13 & $\% 3$ & 21 & $\% 0,5$ & & \\
\hline 17 & $\% 2$ & & & & \\
\hline 19 & $\% 1,5$ & & & & \\
\hline 23 & $\% 1,5$ & & & & \\
\hline 25 & $\% 1,5$ & & & & \\
\hline
\end{tabular}

Tablo-2 Akım Harmonikleri İçin Maksimum Yük Akımına (IL) Göre Sınır Değerler [7]

\begin{tabular}{|c|c|c|c|c|c|c|}
\hline \multicolumn{7}{|c|}{ Tek Harmonikler } \\
\hline ISC/IL & $<11$ & $11 \leq h<17$ & $17 \leq h<23$ & $23 \leq \mathrm{h}<35$ & $35 \leq h$ & TTB \\
\hline$<20$ & 4.0 & 2.0 & 1.5 & 0.6 & 0.3 & 5.0 \\
\hline $20<50$ & 7.0 & 3.5 & 2.5 & 1.0 & 0.5 & 8.0 \\
\hline $50<100$ & 10.0 & 4.5 & 4.0 & 1.5 & 0.7 & 12.0 \\
\hline $100<1000$ & 12.0 & 5.5 & 5.0 & 2.0 & 1.0 & 15.0 \\
\hline$>1000$ & 15.0 & 7.0 & 6.0 & 2.5 & 1.4 & 20.0 \\
\hline
\end{tabular}

Tablo-3 Fliker Şiddeti İçin Sınır Değerler [7]

\begin{tabular}{|c|c|}
\hline $\begin{array}{c}\text { Fliker Şiddeti } \\
\text { Endeksi }\end{array}$ & $\begin{array}{c}\text { Sinır } \\
\text { Değerler }\end{array}$ \\
\hline Pst & $\leq 1.0$ \\
\hline Plt & $\leq 0.8$ \\
\hline
\end{tabular}

\section{MATERYAL VE YÖNTEM}

\section{1. Ölçüm Cihazı}

$\mathrm{Bu}$ çalışmada, şebekeden güç kalitesi verilerini almak için ION7550/ION7650 kodlu güç ve enerji ölçüm cihazı kullanılmıştır. $\mathrm{Bu}$ cihaz birçok değişkeni ölçebilmektedir; ama bu çalışmada sadece harmonik ve fliker ölçümleri yapılmıştır. $\mathrm{Bu}$ analizörün tüm tekilçoğul harmonikleri (63. harmoniğe kadar ölçüm yapabilmektedir), THB değerlerini ve fliker şiddetini ölçme özelliğine sahiptir [8].

\section{2. Ölçümler}

Ölçümler, Gölbaşı/Adıyaman'da kurulmuş olan DAĞPEN AKMKENT (güneş santralinden bir görüntü şekil-1'de verilmektedir) isimli güneş santralinde 2014 yılında yapılmıştır. Ölçümler bir şebeke analizörü

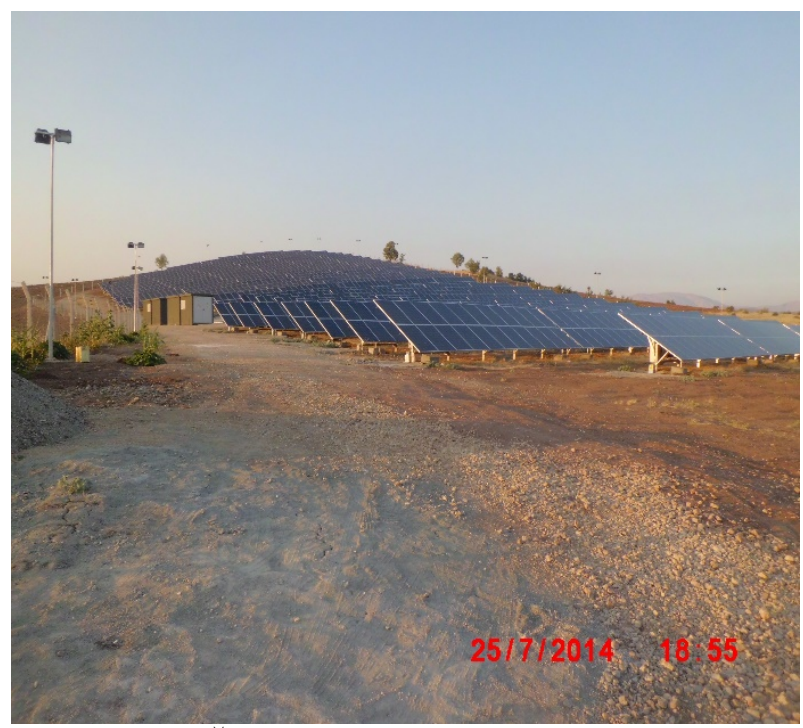

Şekil 1. DAĞPEN AKMKENT GES’ten bir görüntü yardımıyla şebekenin OG tarafından yapılmış ve bu analizörün bağlantı şekli şekil-2 ve şekil3'te görülmektedir. Ölçümlerin yapıldığı sisteme ait tek hat şeması ek’te sunulmuştur. 


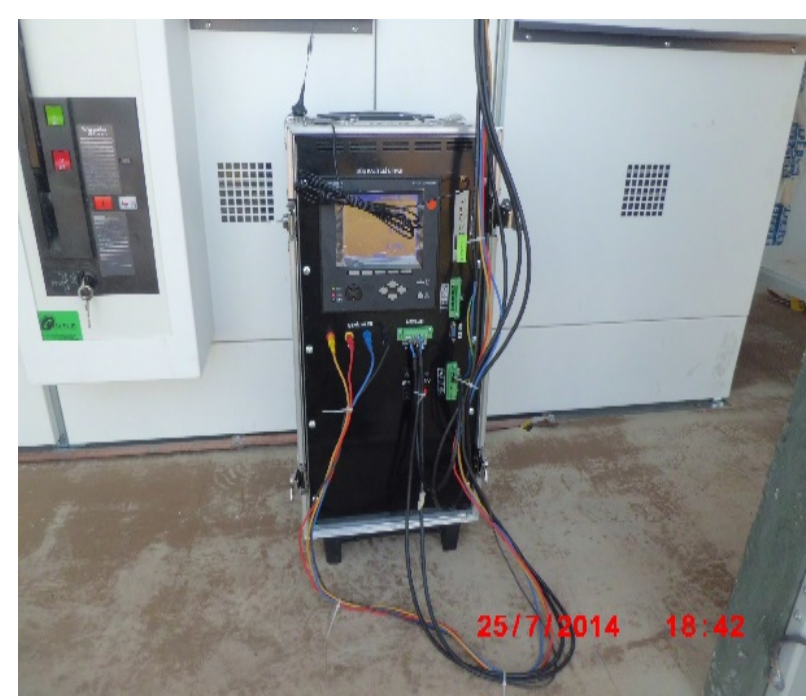

Şekil 2. Kullanılan Şebeke Analizörünün Bağlantı Şekli

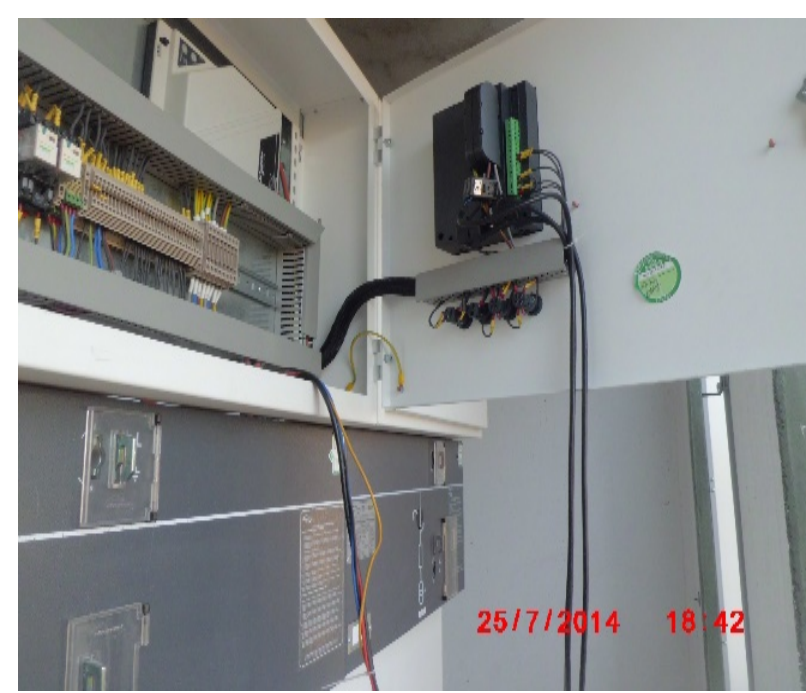

Şekil 3. Şebeke analizörünün OG tarafına bağlantı şekli

Sistemde var olan trafonun etiket değerleri Tablo-4'te, modülerin etiket değeri Tablo-5'te ve kullanılan inverterlerin etiket değerleri ise Tablo-6'da verilmiştir.

Tablo 4. Trafo Etiket Değerleri

\begin{tabular}{|l|l|}
\hline Gerilim & $33 / 0,4 \mathrm{kV}$ \\
\hline Güç kVA & 630 \\
\hline$U_{\mathrm{k}}(\%)$ & 4,5 \\
\hline Bağlantı Grubu & DYN11 \\
\hline Tipi(TSPH) & $11806 / 900$ \\
\hline Marka & ABB \\
\hline Makine No & 1LTR0014295 \\
\hline İmal Y1l & 2012 \\
\hline Standart No & IEC 60076-1 \\
\hline Gerilim(kV)kad.1 & $28,5 / 0,4$ \\
\hline Gerilim(kV)kad.2 & $30 / 0,4$ \\
\hline Gerilim(kV)kad.3 & $31,5 / 0,4$ \\
\hline Gerilim(kV)kad.4 & $33 / 0,4$ \\
\hline Gerilim(kV)kad.5 & $34,5 / 0,4$ \\
\hline
\end{tabular}

Tablo 5. Modüllerin Etiket Değerleri

\begin{tabular}{|l|c|}
\hline \multicolumn{2}{|c|}{ MODÜLLER } \\
\hline Üretici Firma & Yingli solar \\
\hline Tipi & Polikristal \\
\hline $\begin{array}{l}\text { Maksimum } \\
\text { Modül Gücü }\end{array}$ & $250 \mathrm{Wp}$ (watt-peak) \\
\hline Boyutları & $1650 x 990 \times 40 \mathrm{~mm}$ \\
\hline $\begin{array}{l}\text { Toplam Modül } \\
\text { Sayısı }\end{array}$ & 2000 adet \\
\hline $\begin{array}{l}\text { İzin Verilen } \\
\text { Çalışma Sıcaklığ } 1\end{array}$ & $\left(-40^{\circ} \mathrm{C}\right)-\left(+85^{\circ} \mathrm{C}\right)$ \\
\hline İmalat Yılı & 2013 \\
\hline
\end{tabular}

Tablo 6. İnverterlerin Etiket Değerleri

\begin{tabular}{|l|l|}
\hline İmalatçı & Danfoss \\
\hline Tipi & TLX Pro+ 15 kW \\
\hline $\begin{array}{l}\text { Toplam İnverter } \\
\text { Sayısı }\end{array}$ & 29 adet \\
\hline $\begin{array}{l}\text { Maksimum Giriş } \\
\text { Gerilimi }\end{array}$ & $1000 \mathrm{~V}$ (DC) \\
\hline Çıkış Gücü (AC) & $15 \mathrm{~kW}$ \\
\hline Üretim Yı11 & 2013 \\
\hline
\end{tabular}

\subsubsection{Harmonik Ölçümleri}

Harmonikler, doğrusal olmayan yüklerden ya da generatörlerden kaynaklanan güç kalitesi problemlerindendir. Frekansı $50 \mathrm{~Hz}$ dışında kalan tüm sinyaller harmonik olarak değerlendirilir. Harmonik ölçümleri, akım ve gerilim harmonikleri olarak sınıflandırılmıştır. Ayrıca akım ve gerilime ait THB değerlerinin her biri de kendi başlı̆̆ verilmektedir.

\section{A. Gerilim Harmonikleri Ölçümleri}

Gerilim harmoniklerinden 3, 5 ve 7. harmonikler dıșındaki harmoniklerin değerleri çok küçük olduğu için dikkate değer bulunmamıştır. Şekil-4, şekil-5 ve şekil'ya bakıldığında 3, 5, 7. harmoniklerin istenen sinır değerler içinde olduğu Tablo-1'den anlaşılmaktadır. Gerilimdeki THB'nin (şekil-6) ise gün boyu sınır değerin (\%3) üstünde olduğu görülmektedir. Tekil gerilim harmoniklerinin içinde en büyük değere sahip olan 5 . harmonik (250 Hz) olarak görülmektedir. 


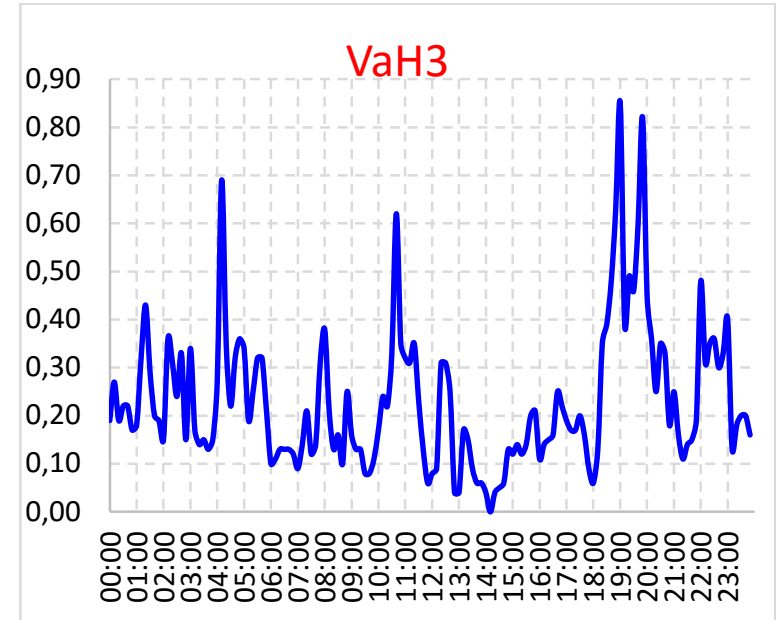

Şekil 4. Gerilime ait 3. Harmonik

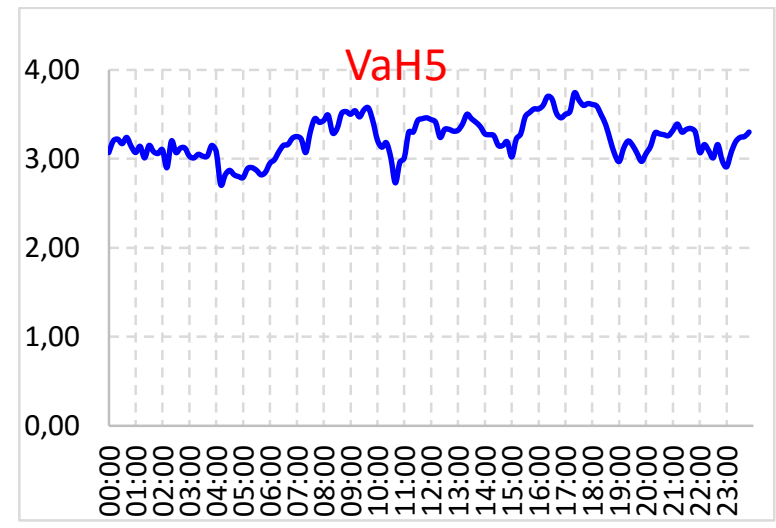

Şekil 5. Gerilime ait 5. Harmonik

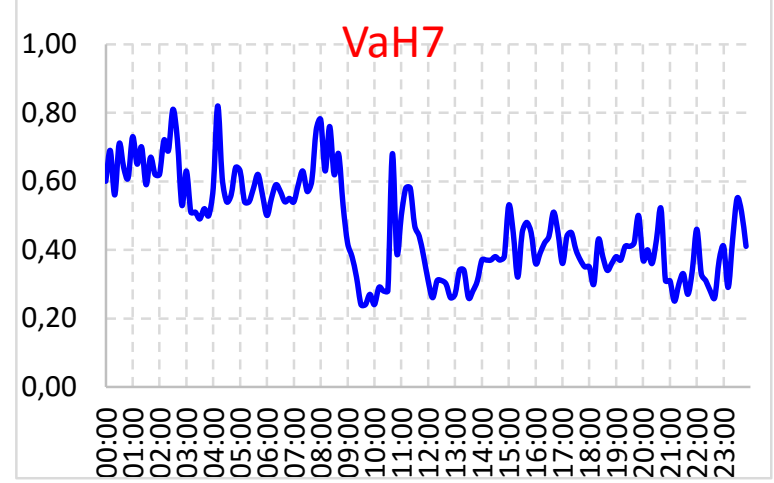

Şekil-6: Gerilime ait 7. Harmonik

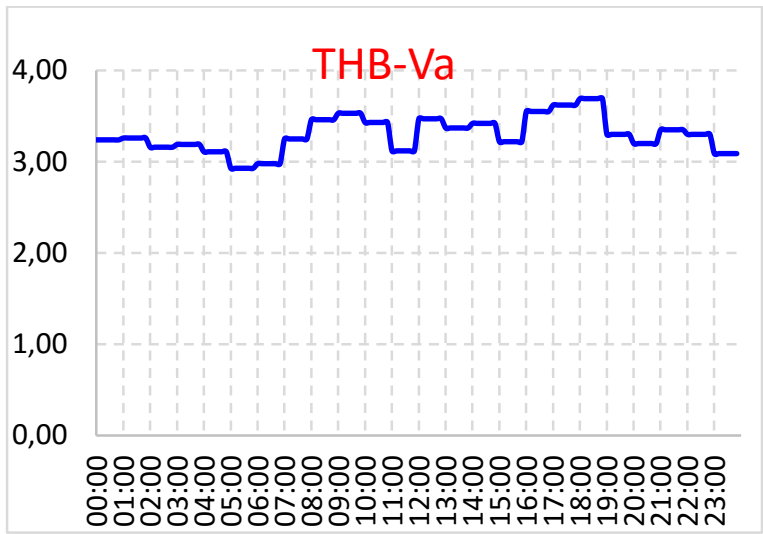

Şekil 7. Gerilime ait THB değeri

\section{B. Akım Harmonikleri Ölçümleri}

Gerilimde olduğu gibi akım harmoniklerinde de 3, 5, 7 haricindeki harmoniklerin değerleri çok küçük olduğundan grafikleri incelemeye alınmamıştır. Şekil-9, şekil-10 ve şekil-11'e bakıldığında; akımdaki bu tekil harmoniklerin hiçbirinin sınır değerlerini aşmadığı görülmektedir. Akım harmoniklerinde de gerilim harmoniklerinde olduğu gibi 5. harmoniğin baskın olduğu görülmektedir. Şekil-9'a bakıldı̆̆ında; saat 07:00 ve 18:00 civarında 5. harmonikte ani artışlar görülmektedir. Aynı durum 7. harmonik için de geçerlidir. Bu durumların sebebinin; güneş panallerinin devreye alınıp devreden çıkarılmasının neden olduğu düşünülmektedir; çünkü yukarıda bahsedilen saatler güneşin doğuş ve batış saatlerine denk gelmektedir. Akıma ait THB değerini gösteren şekil-11 incelendiğinde ise yine saat 07:00 civarında THB'nin sınır değerini (\%5) aştığ1 görülmektedir. Aynı şekilde bunun nedeninin de sabah saatlerinde GES'in devreye alınması olduğu sanılmaktadır.

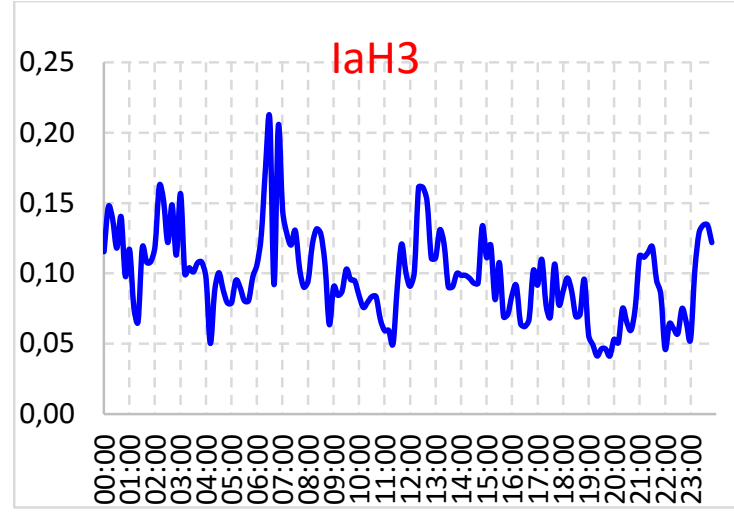

Şekil 8. Akıma ait 3. Harmonik 


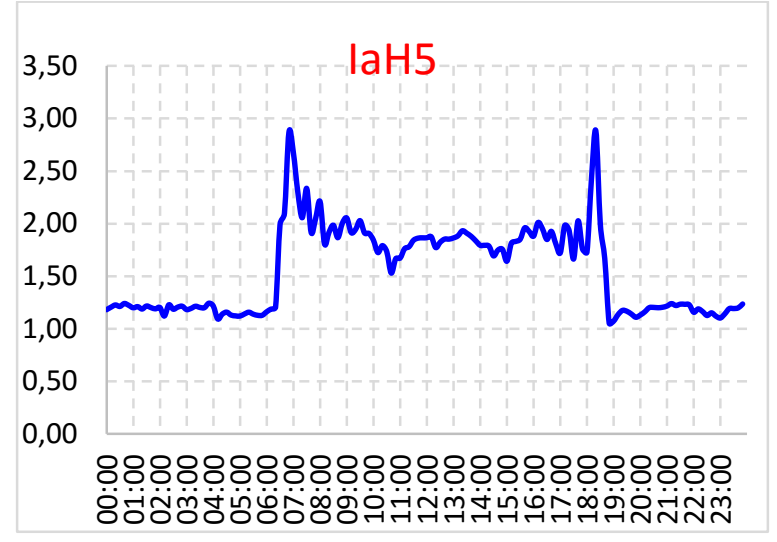

Şekil 9. Akıma ait 5. Harmonik

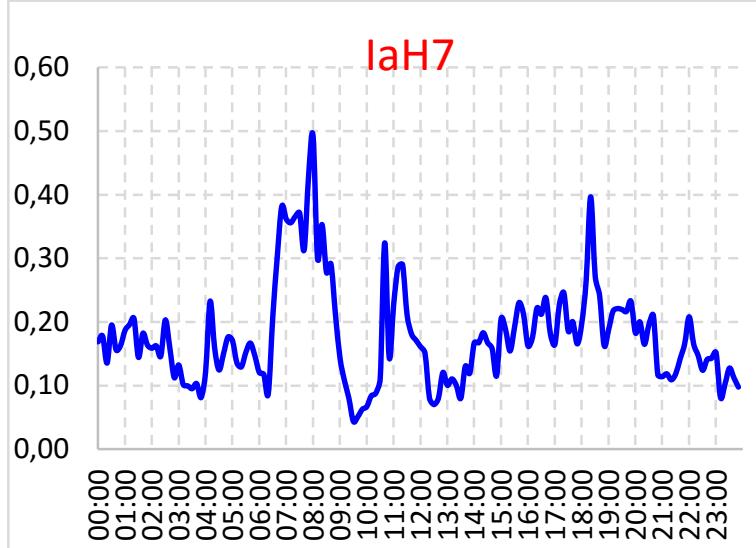

Şekil 10. Akıma ait 7. Harmonik

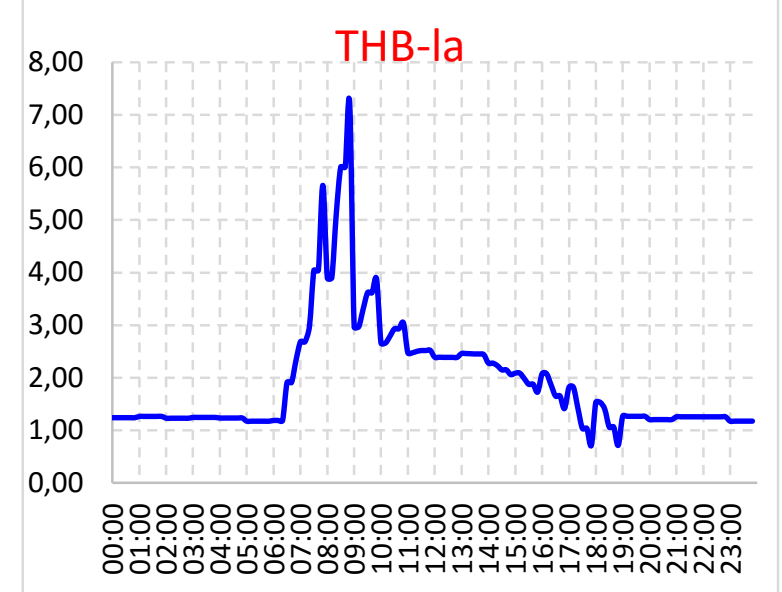

Şekil 11. Akıma ait THB değeri

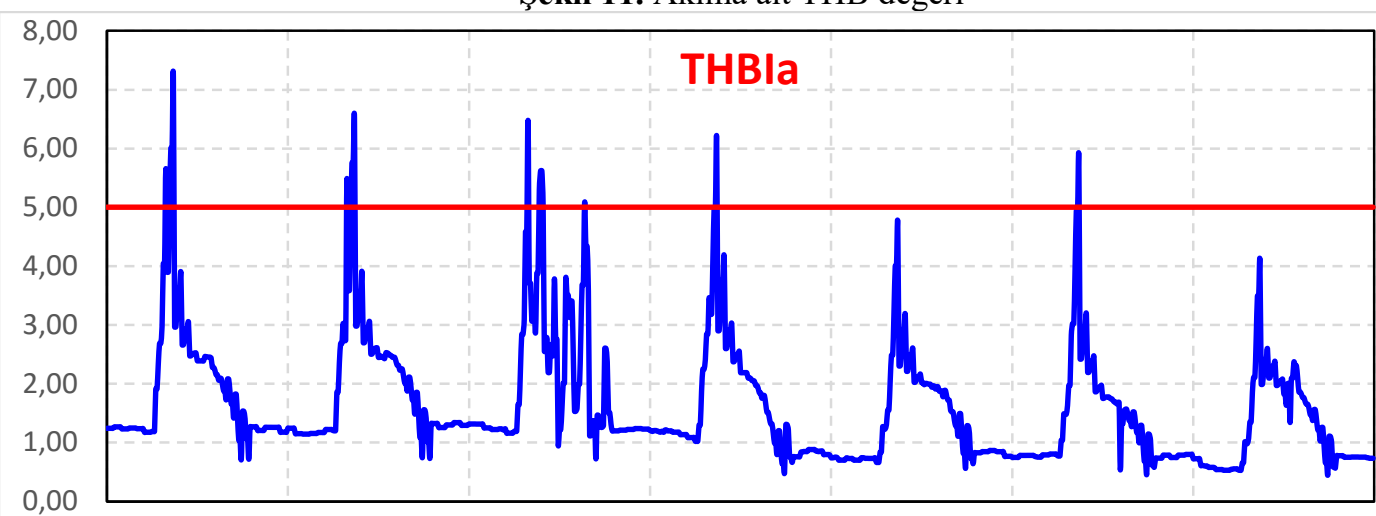

30.9.14 00:00 1.10.14 00:00 2.10.14 00:00 3.10.14 00:00 4.10.14 00:00 5.10.14 00:00 6.10.14 00:00 7.10.14 00:00

Şekil 12. Akıma ait 7 günlük THB değerleri

Şekil-12'deki grafik, 30.09.2014 ile 07.10.2014 tarihleri arasındaki 7 gün için akıma ait THB değerlerini göstermektedir. Şekil-12 analiz edildiğinde; 5 gün, günün belli saatlerinde THB değerlerinin aşıldığı kalan 2 gün içinde ise THB'nin sınır değerleri içinde kaldığı görülmektedir. THB'nin sınır değerinin aşıldığg 5 günün her birinde yaklaşık olarak aynı saatlerde THB'nin sınır değerlerinin aşıldığı ve bu saatlerin de güneşin doğuş vakitlerine denk geldiği görülmektedir. Bu olumsuzluğun sebebinin GES'in o saatlerde devreye alınması olduğu öngörülmektedir. $\quad 02.10 .2014$ tarihindeki THB değerlerinin çok değişken olduğu şekil12'den gözlemlenmektedir. Bu duruma; şebekeye bağlı liner olmayan yükler, GES'in gün içinde hava durumundan dolayı devreye girip çıkmalarından kaynaklanmış olabilir. 


\section{Fliker Ölçümleri}

Fliker ölçümleri; onar dakikalık aralıklarla ölçülen kısa dönem (Pst) ve 12 tane ardışık Pst değeri kullanılarak (2 saatlik ölçüm) elde edilen uzun dönem (Plt) ölçümlerinden oluşmaktadır. Şekil-13 ve şekil14 'teki grafiklerde bulunan kırmızı çizgiler Pst ve Plt'nin sınır değerlerini göstermektedir. Bu durumda grafikler incelendiğinde; Pst'nin gün içinde üç defa sınır değerleri aştığı görülmektedir. Plt ise sadece bir kere sınır değeri aşmıştır. Şekil-13'e bakıldığı zaman Pst değerinin saat 08:00 ile 09:00 arasında 2'nin üstünde bir değere çıktığ1 gözlemlenmektedir. $\mathrm{Bu}$ durum, şebekede bu saat aralıklarında ani bir yük artışının olduğunu göstermektedir.

Genel olarak şebekenin (şekil-13 ve şekil-14'ten yola çıkarak) fliker açısından iyi durumda olduğu kanısı çıkarılabilir.

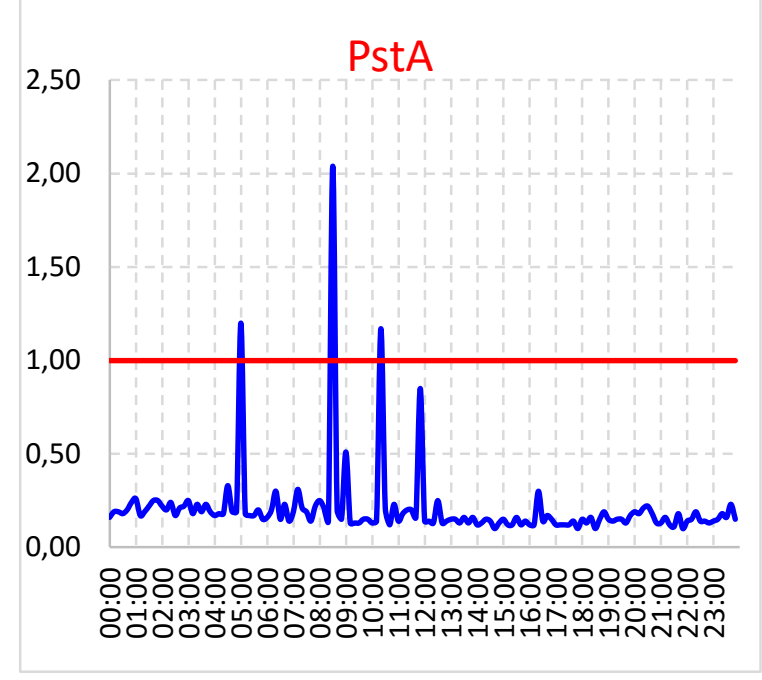

Şekil 13. Pst Ölçümü

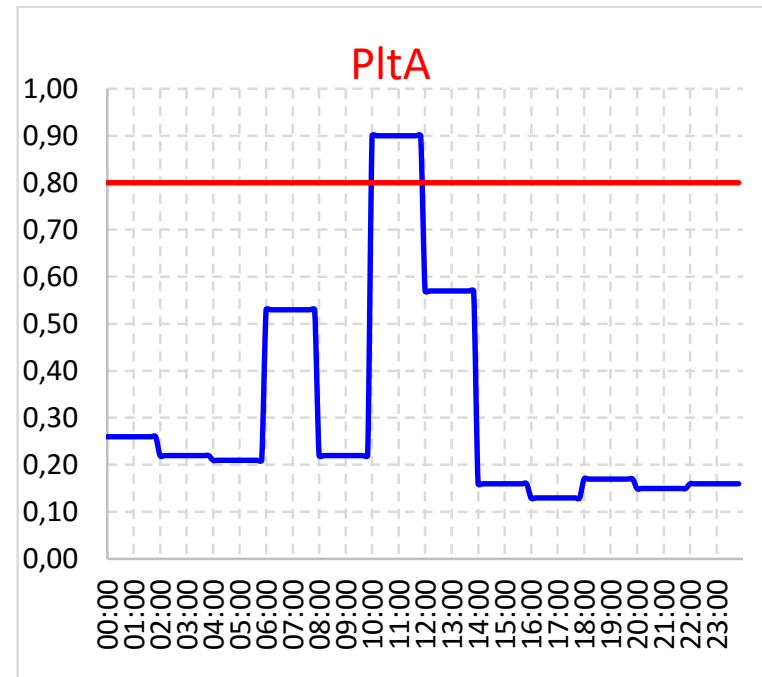

Şekil 14. Plt Ölçümü

\section{Sonuçlar}

Bu makalede; Adıyaman'ın Gölbaşı ilçesinde kurulu olan (kapasitesi $1 \mathrm{MW}$ ) DAĞPEN AKMKENT GES'in şebekeye bağlandığı noktadaki OG barasından bir şebeke analizörü (ION7550/ION7650) vasıtasıyla akım ve gerilim harmonik verileri ile fliker şiddeti verileri güç kalitesi değerlendirmesi yapmak üzere alınmıştır. Şebekeden alınan bu veriler grafiklere dökülmüştür. Oluşturulan bu grafiklerin analizi sonucunda; akım ve gerilimde 3, 5, 7 gibi tekil harmoniklerin sınır değerler içinde kaldığı görülmüştür. Bir günlük veriler incelendiğinde; gerilime ait THB değerinin gün boyu sınır değerini (\%3) aştığı gözlemlenmiştir. Akıma ait THB değerinin ise sadece günün belli bir saatinde kısa bir süreliğine sınır değerini (\%5) geçtiği görülmüştür. Sınır değerin aşıldığı bu vakit sabah GES'in devreye girdiği saate tekabül ettiği için bu sınır ihlaline GES'teki inverterlerin sebep olabileceği düşünülmektedir. Akıma ait bir haftalık THB değerleri incelendiğinde ise; THB'nin genel olarak sınır değerini geçmediği sadece belli saatlerde kısa süreliğine sınır değerlerinin aşıldığı anlaşılmaktadır. Buna da günün o saatinde güç elektroniği tabanlı bir anahtarlama işleminin sebep olacağı vurgulanmıştır. Yani GES'in devreye girmesi olarak düşünülmektedir. Fliker açısından sistemin genel olarak iyi olduğu saptanmıştır; ama Pst değerinin gün boyu $3 \mathrm{kez}$ sınır değerini aştığı ve bunlardan birinde sınır değerin yaklaşık iki katına kadar çıktığı gözlerden kaçmamaktadır.

Tüm bu değerlendirmeler sonunda; bir GES santralinin devreye alınması ve devreden çıkarılması sırasında şebekede geçici de olsa harmonik değerlerini yükselttiği anlaşılmıştır. Bu durumu gidermek için ise şebekeye bir pasif filtreleme işleminin yapılması önerilmektedir.

\section{Kaynaklar}

[1]. R. Polikar, "The Story of Wavelets”, Physics and Modern Topics in Mechanical and Electical Engineering, N. Mastorakis (Eds.), World Scientific and Electrical Engineering Society, 1999.

[2]. Yilmaz, M., "Elektrik Sistem Tasarımında Harmoniklerin Giderilmesi İçin Bir Analiz" Yüksek Lisans Tezi, 2006.

[3]. Yalcın, T., Ozgonenel, O., “Deneysel Kip Çözümleme İle Güç Kalitesi Bozukluklarından Özellik Vektörü Çıkarımı" IEEE Conference Publications, Pages: 1-4, 2012.

[4]. Yıldırım, Ö., Erişti, B., Erişti, H., Ünal, S., Erol, Y., Demir, Y., "FPGA Tabanlı Bir Güç Kalitesi İzleme Sistemi” IEEE Conference Publications, Pages: 1292-1295, 2015. 
[5]. Süslüoğlu, B., Gök, A., Özdemirci, E., "İzmir Bölgesinde Belli Noktalarda Fliker Durum Değerlendirmesi” 5. Enerji Verimliliği ve Kalitesi Sempozyumu, 2013.

[6]. Akmaz, D., Mamiş, M. S., "Ayrık Fourier Dönüşümü İle Güç Sistemlerinde Harmonik Analizi” IEEE Conference Publications, Pages: 1397-1400 , 2015.

[7]. Keçecioğlu, Ö.F., Tekin, M., Gani, A., Sarı, M., Şekkeli, M., "Endüstriyel Isı Santrallerinde Enerji Kalitesi Ölçümü ve Değerlendirilmesi, Kahramanmaraş Sütçü İmam Üniversitesi Örneği”, 6. Enerji Verimliliği ve Kalitesi Sempozyumu, 2015.

[8]. Elektrik Dağıtımı Ve Perakende Satışına İlişkin Hizmet Kalitesi Yönetmeliği, Enerji Piyasası Düzenleme Kurumu, 2012.

[9]. PowerLogic ${ }^{\mathrm{TM}}$ ION7550/ION7650 Kullanım Kilavuzu.

[10]. Y1lmaz, A. S., Keçecioğlu, Ö. F., Tekin, M., Özalp, A., Şekkeli, M., "Güç Kalitesi İçin Saha Çalışması: Kahramanmaraş Örneği” Mühendislik Ve Fen Bilimleri Dergisi, Akademik Platform, Sayfa: 22-34, Cilt: 2, Sayı: 3, 2014.

[11]. Tekin, M., Yılmaz, A. S., "Güç Sistem Harmoniklerinin Ayrık Hartley Dönüşümü İle Analizi” KSU-JES, Vol: 18, No:1, 2015.

[12]. İnan, A., Ermiş, N., “Ara Harmoniklerden Kaynaklanan Gerilim Kırpışmasının Aydınlatma Üzerindeki Etkileri” II. Ulusal Aydınlatma Sempozyumu Ve Sergisi Bildirileri, 2003.

[13]. Kakilli, A., Tunçalp, K., Sucu, M., "Harmoniklerin Reaktif Güç Kompanzasyon Sistemlerine Etkilerinin incelenmesi ve Simülasyonu" Firat Üniv. Fen ve Müh. Bil. Dergisi 20 (1), 109-115, 2008.

[14]. Acarkan, B., Kılıç, O., İnan, A., “Alçak Gerilimde Tek Fazlı Yükler İçin Harmonik Akım Sınırları” III. Elektrik, Elektronik ve Bilgisayar Mühendisliği Sempozyumu, ELECO, Sayfa: 8488, 2004.

[15]. Şekkeli, M., Yılmaz, A. S., "Bir Taş Kırma Tesisinde Güç Kalitesi Seviyesinin Ölçümü ve Değerlendirilmesi” Mühendislik Bilimleri Dergisi, Cilt:15, Sayı:3, Sayfa: 317-323, 2009.

[16]. Tuğ, L., Yavuz, C., "Alçak Gerilimde Aktif Filtre ile Akım Harmoniklerinin Etkisinin Azaltılması" Akademik Platform, 2013.

[17]. Ünsar, Ö., Salor-Durna, Ö., Çadırcı, I., Ermiş, M., "Elektrik Sistemi Ortak Bağlantı Noktalarında Harmonik Akım Katkılarının Ölçüme Dayalı
Olarak Belirlenmesi” IEEE Conference Publications, Pages: 1-4, 2012.

[18]. Yılmaz, İ., Salor-Durna, Ö., Çadırc1, I., Ermiş, M., "Sinüzoidal Kodlama İle Orta Frekanslı Endüksiyon Ergitme Ocaklarının Güç Kalitesinin İncelenmesi” IEEE Conference Publications, Pages: 1-4, 2013.

[19]. Kopicka, M., Ptacek, M., Toman, P., “Analysis Of The Power Quality And The Impact Of Photovoltaic Power Plant Operation On LowVoltage Distribution Network” IEEE Conference Publications, Pages: 99-102, 2014.

[20]. Sezgin, E., Göl, M., Salor, Ö., “Durum Kestirimi Kullanılarak Ortak Bağlantı Noktasına Bağlı Tesislerin Harmonik Akım Katkılarının Belirlenmesi” IEEE Conference Publications, Pages: 2062-2065, 2015.

[21]. Gorecki, K., Szmajda, M., “The Power Quality in Low-Power Solar Off-Grid System” IEEE Conference Publications, Pages: 244-248, 2014.

[22]. Nourollah, S., Zargari, A., “Assessing Power Quality Of Power System Using FICA Algorithm” Advanced Computational Techniques in Electromagnetics, Pages:1-20, 2014.

[23]. El-Amin, I. M., Al-Elyani, A., Shuaib, A., "Power Quality Indices: A Saudi Steel Mill Case Study” International Conference On Computing, Electrical And Electronıc Engıneerıng (ICCEEE), 2013. 